\section{Acute kidney injury occurs only rarely in patients with Kawasaki disease}

Advance online publication, 20 September 2017; doi:10.1038/pr.2017.191

To the Editor: Chuang et al. (1) investigated the clinical characteristics and laboratory data including serum creatinine levels of 336 Taiwanese patients with Kawasaki disease (KD) to determine the prevalence of acute kidney injury (AKI) and its associated factors. They reported that $28 \%$ of their patients had AKI, with young age and a high alanine transaminase level being associated with AKI in these patients.

KD causes systemic vasculitis that may include involvement of the kidneys. However, with the exception of sterile pyuria and trace proteinuria, kidney involvement in $\mathrm{KD}$ is uncommon and AKI has been reported only rarely in patients with KD (2).

We carried out a retrospective review of electronic medical records for clinical, laboratory, and echocardiographic data in 249 Japanese children with KD admitted to Niigata City General Hospital between April 2007 and March 2017. KD was defined according to the AHA 2004 diagnostic criteria (3), while AKI was defined as a serum creatinine level $\geq 1.5$ times the upper limit of normal age-specific serum creatinine reference levels (1). The study showed that no patient developed AKI (Table 1). Although the laboratory data were similar to those reported by Chuang et al. (1), our patients had fewer coronary artery abnormalities (CALs) during the acute phase $(7.2 \%)$ compared with patients in the earlier study (21.7\%).

Although the reasons are unclear why these two studies showed a different prevalence of AKI in patients with $\mathrm{KD}$, it is possible that differences in disease severity may have affected the results. Because the study of Chuang et al. was performed in a university hospital, they may have included patients with more severe KD than in the vast majority of non-university hospitals. Our study was performed in a nonuniversity hospital, with the prevalence of CALs during the acute phase of the study being similar to that in a recent nationwide survey of KD in Japan (8.1\%) (4) and also that in a large epidemiological study of $\mathrm{KD}$ in Taiwan (7.2\%) (5). These findings suggest that our study is a reliable assessment of the clinical features of $\mathrm{KD}$ in the general population and indicates that AKI occurs only rarely in most patients with KD.
Table 1. Clinical and laboratory data of 249 patients with KD

\begin{tabular}{|c|c|}
\hline Variables & $n(\%)$ or median (range) \\
\hline Male/Female & $159 / 90(63.9 \% / 36.1 \%)$ \\
\hline Age (years) & $2.42(0.17-10.5)$ \\
\hline \multicolumn{2}{|l|}{ Age category } \\
\hline$<0.5$ years & $12(4.8 \%)$ \\
\hline $0.5-2$ years & $95(38.2 \%)$ \\
\hline$>2$ years & $142(57.0 \%)$ \\
\hline Symptoms onset of KD diagnosis (days) & $5(3-10)$ \\
\hline \multicolumn{2}{|l|}{ Laboratory data } \\
\hline WBC $(\mathrm{k} / \mu \mathrm{l})$ & $16.24(2.14-19.02)$ \\
\hline$W B C>15 \mathrm{k} / \mu \mathrm{l}$ & $119(47.8 \%)$ \\
\hline Platelet $(\mathrm{k} / \mu \mathrm{l})$ & $343(108-791)$ \\
\hline Platelet $>450 \mathrm{k} / \mu \mathrm{l}$ & $34(13.7 \%)$ \\
\hline CRP (mg/dl) & $8.03(0.29-31.93)$ \\
\hline $\mathrm{CRP}>3 \mathrm{mg} / \mathrm{dl}$ & $225(90.4 \%)$ \\
\hline $\operatorname{ALT}(\mathrm{U} / \mathrm{I})$ & $114.7(6-1215)$ \\
\hline $\mathrm{ALT}>40 \mathrm{U} / \mathrm{I}$ & $117(47.0 \%)$ \\
\hline Urine $\mathrm{WBC} \geq 10 / \mathrm{HPF}$ & $46(32.0 \%)$ \\
\hline \multicolumn{2}{|l|}{ Treatment } \\
\hline $\mathrm{IVIG}+\mathrm{AP}$ & $206(82.7 \%)$ \\
\hline $\mathrm{IVIG}+\mathrm{AP}+\mathrm{CS}$ & $37(14.9 \%)$ \\
\hline AP only & $6(2.4 \%)$ \\
\hline \multicolumn{2}{|l|}{ Outcome } \\
\hline AKI & $0(0.0 \%)$ \\
\hline Coronary artery abnormality & $18(7.2 \%)$ \\
\hline Coronary artery aneurysm & $2(0.8 \%)$ \\
\hline Coronary artery ectasia & $16(5.6 \%)$ \\
\hline
\end{tabular}

AKI, acute kidney injury; AP, antiplatelet therapy; CS, corticosteroid therapy; IVIG, intravenous immunoglobulin therapy; KD, Kawasaki disease; WBC, white blood cells.

Disclosure: The authors declare no conflict of interest.

Toru Watanabe', Tadaaki Abe ${ }^{1}$ and Shinya Tsukano ${ }^{1}$

${ }^{1}$ Department of Pediatrics, Niigata City General Hospital, Niigata, Japan.

Correspondence: Toru Watanabe (twata@hosp.niigata.niigata.jp)

\section{REFERENCES}

1. Chuang GT, Tsai IJ, Lin MT, Chang LY. Acute kidney injury in patients with Kawasaki disease. Pediatr Res 2016;80:224-7.

2. Watanabe T. Kidney and urinary tract involvement in Kawasaki disease. Int J Pediatr 2013;2013:831-4. 


\section{Letter to the Editor}

3. Newburger JW, Takahashi M, Gerber MA, et al. Diagnosis, treatment, and long-term management of Kawasaki disease: a statement for health professionals from the Committee on Rheumatic Fever, Endocarditis and Kawasaki Disease, Council on Cardiovascular Disease in the Young, American Heart AssociationCirculation 2004;110: 2747-71.
4. Makino N, Nakamura Y, Yashiro M, et al. Descriptive epidemiology of Kawasaki disease in Japan, 2011-2012: from the results of the 22nd nationwide survey. J Epidemiol 2015;25:239-45.

5. Lin MC, Lai MS, Jan SL, Fu YC. Epidemiologic features of Kawasaki disease in acute stages in Taiwan, 1997-2010: effect of different case definitions in claims data analysis. J Chin Med Assoc 2015;78:121-6. 